\title{
Lei de Drogas, Código Penal Militar e o Princípio Insignificância: da Necessida- de da Sanção à Humanização da Pena
}

\section{Isaac Newton Lucena Fernandes de Queiroz}

Advogado, ex-cadete do PMMG aprovado em 20 lugar no Concurso para o Curso de Formação de Oficiais em 2017. Formado em Direito pela Universidade Federal do Rio Grande do Norte, pós-graduado em Direito Administrativo e Mestre em Desenvolvimento e Meio Ambiente pela mesma instituição. Exerce o cargo de Técnico-Administrativo no Universidade Federal do Rio Grande do Norte.

\section{George Andrade Werner}

Aspirante do Polício Militor de Minas Gerais, ingresso no instituição em 2007, através do Curso técnico em segurança pública (PMMG). Concluinte do Curso de formação de sargentos (PMMG) no ono de 2011. Bacharel em Direito, concluído no ano de 2016 pela Faculda-de de Direito e Ciêncios Sociais do Leste de Minas (FADILESTE). Concluinte do Curso de Formação de oficiais (PMMG) do ano de 2018.

\section{Eduardo Tadeu Silva Costa}

Aspirante da Polício Militar de Minas Gerais, ingresso na instituição em 2006, através do Curso técnico em segurança público (PMMG). Concluinte do Curso de formação de sargentos (PMMG) no ono de 2010. Bacharel em Direito, concluído no ano de 2015 pela Faculda-des Kennedy de Minas Gerais. Concluinte do Curso de Formação de oficiais (PMMG) do ano de 2018.

\author{
Data de recebimento: $27 / 06 / 2017$ \\ Data de aprovação: 03/08/2018 \\ DOI: 10.31060/rbsp.2018.v12.n1.815
}

\section{Resumo}

A norma penal tem a função de manter a coesão social, punindo o comportamento desviante oo mesmo tempo em que o previne no âmbito da reação social jurídica oo crime. Durante a história da humanidade, a norma penal já se manifestou em um extenso rol de penas cruéis, mas está hoje ela acompanhada dos valores de humanização universalmente aceitos. No meio militar, embora mais severas, essas diferenciações entre as penas devem guardar openas a discrepâncio necessária à preservaçõo dos bens jurídicos distintos. Exemplo disso seria a inadmissõo do princípio do insignificâncio oo porte de drogas por militar, punido igualmente àquele que trafica. o objetivo do trabalho é suscitor reflexõo sobre o quadro social de epidemia do uso de drogas no mundo moderno, bem como dos seus impactos sociais e da necessidade de repensar a matéria como questão de saúde pública, inclusive e especialmente no meio policial militar. Utilizando dados empíricos secundários, analisodos à luz de entendimentos doutrinários e jurisprudenciais, a metodologia é descritiva e tombém exploratório. Como resultado, a discussão avança na busca pela congruêncio da punição com princípios constitucionais de proporcionalidade e individualização da pena, amparado ainda na necessária reflexão sobre a função da pena e seus efeitos no meio costrense.

Palavras -Chave

Lei de Drogos. Código Penal Militor. Policial Militor 


\begin{abstract}
Drug Law, Military Penal Code and the insignificance principle: from the necessity of sanctioning to penalty humanization.

The criminal law has the function of maintaining social cohesion, punishing while preventing the deviont behovior in the context of the social reaction to crime. Throughout the history of mankind, people have endured under an extensive list of cruel punishments, but today the punitive law is impregnated with the universal values of humanization. In the military milieu, yet more severe, the differentiation between sentences must preserve only the necessary discrepancy for the preservation of distinct interests. The inadmissibility of the principle of insignificance to the possession of drugs by military, punished in the same way as the one who traffics, would be an example of that difference of treatment compared with regular criminal low. The objective of the study is to take into account the social context of the drug use epidemics in the modern world, its social impacts and the need to rethink the issue as a public health issue, including and especially in the military police. Using secondary empirical data, analyzed in the light of doctrinal and jurisprudential understandings, the methodology is descriptive and also exploratory. As results, the discussion advances as it seeks for the consistency of state punishment under the constitutional principles of proportionality and penalty individualization, and the necessary reflection on its punitive function and effects in the military milieu.
\end{abstract}

\title{
Keywords
}

Drug Legislation. Military Criminal Low. Military Police 


\section{INTRODUCÃO}

A sançáo faz parte do direito, sendo um elemento que integra a própria autoridade estatal. Não por menos é que grande parte das normas jurídicas, ou mesmo todas elas, de um modo ou de outro, regula o uso da força. Éo imperativismo, que para os jusfilósofos positivistas trata-se justamente do poder investido como necessário para a sustentaçáo de uma estrutura estatal moderna, detentora do monopólio do uso da força (SALGADO, 2010).

Isso significa que, para alcançar os objetivos e manter a coesáo social, a organizaçáo necessita se amparar em coerçăo, esta entendida como efeito direto (ou pelo menos da certeza deste pela populaçáo) da repressáo ao comportamento tido por desviante. A coaçăo também seria identificada como um aspecto psicológico ou pedagógico do uso da força, mas geralmente está mais afetaàs relaçóes privadas.

Sem delongas maiores no exame historiográfico da sançăo, mais especificamente a pena, imperioso, contudo, se faz afirmar que elas atendem aos anseios sociais da época, amparadas nos princípios adotados pelos povos ao longo do tempo. Dentre as fases mais conhecidas, como a vingança privada, a lei de talião e os primórdios da adoçáo da compositio, passando pela pena corporal que infligia torturas e suplícios, processos secretos, crueldades, a humanidade evoluiu bastante nesse sentido. No Brasil, durantes as Ordenaçóes Filipinas que vigeram no período colonial, figuravam dentre as principais penas o degrado e a morte, essa podendo ser executada sob diversas formas como fogueira, veneno, forca ou pelourinho. Nessa época não havia sequer separação entre deveres ćivicos e religiosos, pois também era punida com a morte a bruxaria, a sodomia, dentre outras transgressóes de natureza moral. Importante frisar, contudo, que o Rei utilizava de sua soberania para abrandar ou comutar as puniçóes, fazendo-o inclusive com bastante frequência, de forma a centralizar o poder e angariar apoio público (BRETAS; SANT'ANA, 2010).

No caso das instituiçōes militares, em razão da sua natureza de amparo na hierarquia, na ordem e na disciplina, a repressáo às condutas inadequadas sempre foi mais severa. Para a doutrina militar, sua atividade precípua de segurança nacional, no exercício das atribuiçóes conferidas na qualidade de longa manus daquele investido no poder estatal, demandariam maior rigor, de maneira que o poder de coerção seja ainda maior.

Assim é que as penas aplicadas em razão de transgressōes próprias têm uma específica condiçáo de maior severidade. Segundo Jorge César de 
Assis, elas já foram da pena de morte ao desertor e de arrancar a língua ao espião no Egito, de castigos corporais diversos, diminuiçáo compulsória do status social, trabalhos forçados, de decapitaçáo, de degradaçáo e outras igualmente cruéis na Roma Antiga. A França adotava uma pena chamada salto de polé, onde o militar amarrado pelas mãos, preso a uma corda amarrada do mastro de um navio ao convés, era atirado ao mar e içado quantas vezes fosse determinado pelo comandante (ASSIS, 2007).

Quanto ao caso brasileiro, o referido autor cita que os Artigos de Guerra do Conde de Lippe, aprovados em 1763 e em vigor no Brasil colonial, previam a pena de morte para a maioria dos delitos militares, variavam apenas as modalidades da execuçáa. Com a prodlamaçáo da República, o novo Código Penal Militar - CPM, ainda previa diversas modalidades de pena, dentre as quais ainda se incluía a de morte e a de trabalhos forçados, ainda que em tempo de paz. Segundo Bretas e Sant'Anna, a República Velha destinava a pena de prisão celular para a quase totalidade dos crimes políticos e militares, justificadas à época pelo temor de convulsóes intestinas que levassem o país de volta ao império. Apenas quando da promulgaçáo do atual CPM (Decreto-Lei $\mathrm{n}^{\circ} 1.001$, de 21 de outubro de 1969) é que a pena de morte é transportada para crimes cometidos em tempo de guerra (ASSIS, 2007), além de serem adotados outros beneficios oriundos do Código Penal comum.

Vale salientar ainda, que a aplicação da pena capital para alguns crimes cometidos em tempo de guerra alinha-se à vinculaçáo do Brasil ao Segundo Protocolo Facultativo ao Pacto Inter- nacional de Direitos Civis e Políticos (PIDCP), constante do Decreto Legislativo no 311/2009, e também ao Protocolo Adicional à Convençáo Americana sobre Direitos Humanos Referente à Aboliçáo da Pena de Morte, assinado pelo Brasil em 7 de junho de 1994 e em vigor desde a promulgaçáo do Decreto $\mathrm{n}^{\circ} 2.754$, de 27 de agosto de 1998.

Em que pese a penologia ${ }^{1}$ brasileira mostrara evoluçáo social no que tange à reaçáo jurídica do ato delituoso, no caso dos delitos militares ainda há situaçóes delicadas que demandam reflexáo. Há casos em que a puniçáo para o civil e para o militar sáo completamente distintas, da mesma forma que o tratamento de determinadas questóes processuais pelas justiças comum e especial encontra-se bastante discrepante.

Assis (2007) cita como exemplo as discussões que sobrevieram com a Lei no 9.099/95 e também posteriormente com a instalaçáo dos juizados especiais federais e aplicabilidade de seu rito à caserna, que embora superada no âmbito das reiteradas decisóes judiciais, não deixa de suscitar o clamor pela criaçáo de institutos similares na justiça castrense. A celeuma não é sem razão: há doutrina farta que critica a Lei no 9.839/99, a qual inseriu o art. 90-A na Lei dos Juizados vedando a aplicaçáo desta no âmbito militar, afirmando que tal diferenciaçáo afronta o princípio da igualdade de maneira desarrazoada (GOMES, 1997).

No mesmo passo está a discussáo sobre a aplicaçáo da Lei de Drogas (Lein ${ }^{\circ}$ 11.343/2006) — em especial seus institutos despenalizadores —, que embora igualmente pacificada na juris-

1 Penologia é uma ciência fática (logo, empirica), que observa e analisa os acontecimentos e processos que se desenvolvem na realidade material da punição, sendo que seu objeto de estudo sõo as reaçães sociais perante condutos ou sujeitos percebidos como perigosos pela coletividade, segundo Ney Foyet Junior e Carlos Thompson Flores. Penas e Punição. In: Crime, Polícia e Justiça no Brasil. 2014, p. 370. 
prudência pátria sobre a sua não incidência nos delitos militares, ainda encontra vozes discordantes na doutrina, que atentam para uma necessária reflexão sobre a matéria.

De fato, a discussáo tem sua razão de ser. Com a nova Lei de Drogas, o porte de substância ilícita deixou de ser punido com prisão. Isso não significou um enfraquecimento da política de combate aos entorpecentes ilícitos; pelo contrário, de 2005 a 2012, o número de presos por tráfico no Brasil passou de 9\% para 23\% da populaçáo encarcerada no país (LEMGRUBER; BOITEUX, 2014). Entretanto, no meio militar vige o rigor que iguala o porte ao tráfico, açambarcando-os no mesmo instituto penal e isolando o aparato estatal militar da discussáo sobre a epidemia das drogas no Brasil e no mundo. Ademais, o Supremo Tribunal Federal e os demais Tribunais pátrios jáalinhavaram a decisão de não aplicar o princípio da insignificância a esse tipo de delito.

A questão subjacente é: seria tal rigidez necessária, proporcional e útil diante de um quadro generalizado de intenso estresse profissional, como é caso daquele vivenciado pelos policiais militares brasileiros?

É essa, pois, a temática do presente trabalho: refletir sobre a questáo amparando-se em fatos sociais, opondo-os ao tratamento jurídico dispensado pelos tribunais pátrios. O objetivo geral é resgatar a discussáo sobre a política no caso da criminalizaçáo do porte de drogas e as funçōes declaradas da pena: ressocializaçáo e retribuiçáo.

Como metodologia, trabalha-se com dados empíricos secundários, extraídos de publicaçóes especializadas, mostrando que o consumo de entorpecentes por agentes do sistema de segurança revela-se como um problema sério e silencioso. A outra linha metodológica contempla a pesquisa bibliográfica e jurisprudencial sobre o tema no país. O método éo descritivo exploratório, sugerindo ligaçóes entre a situaçáo fática encontrada nos dados empíricos e as suas reverberaçóes não só no âmbito da doutrina e das decisóes judiciais, mas também em como esses elementos sáo pressupostos para o objetivo geral: discutir a funçáo social da pena para esse crime.

Adianta-se, desde já, que o presente trabalho não tem o condão de defender despenalizaçáo ou de moderar a rigidez que a disciplina militar exige dos seus quadros, mas de incluir a justiça militar no universo de discussáo de um grave problema social que não pode ser simplesmente ignorado.

\section{o Consumo de Drogas Lícitas e llícitas por Policiais}

Segundo Salomão Shecaira (2014), o uso de drogas sempre foi constante na espécie humana, tendo se tornado um problema epidêmico com a consolidaçáa do capitalismo sustentada na expansão colonial europeia. Além disso, o desenvolvimento farmacêutico potencializou os efeitos dos entorpecentes, tornando-se um componente essencial para catalisar as suas consequências no âmbito social.

O proibicionismo, movimento que, ora mais forte, ora mais brando, prega pela proibiçáo do consumo de entorpecentes, passou a integrar oâmbito do feixe de atribuiçōes estatais por questóes que nada tinham a ver com saúde pública ou qualquer outra natureza de proteçáo ao indivíduo. As leis proibicionistas no Ocidente surgiram na época em que a Inglaterra, tendo perdido a Guerra do Ópio para a China, deixou de lutar pelo controle da droga para lutar contra ela, no exclusivo intento de sufocar comercialmente o oponente (LEMGRUBER; BOITEUX, 2014). 
Ainda em matéria de proibicionismo, hoje se separam as substâncias em lícitas e ilícitas por questôes de natureza eminentemente política. A bebida alcoólica já foi proibida no mundo ocidental (v.g. a famosa Lei Seca americana) e os efeitos sempre foram negativos: o tráfico foi imediato, as mortes o seguiram; consequentemente, a falência da medida logo se anunciou. Em questóes de saúde pública, contudo, não há estudo conclusivo que indique ser o álcool etilico mais ou menos gravoso à saúde que outras substâncias entorpecentes, inexistindo critério objetivo que justifique sua liberação ou proibição.

Tanto que a bebida é hoje o maior problema quando se fala em drogadiçáo no universo policial militar. De acordo com artigo publicado em 2013 por Edinilsa Souza (SOUZA, 2013), um estudo estatístico realizado na cidade do Rio de Janeiro mostrou que $48,9 \%$ dos militares dedararam beber semanalmente, enquanto $11 \%$ chegam a beber diariamente. Esse dado está diretamente relacionado com o absentésmo no meio militar $-4,4 \%$ dos policiais afirmam já terem se atrasado ou faltado em funçáo da bebida.

Descobriu-se, ainda, que 6,4\% dos militares mesclam drogas lícitas com drogas ilícitas, ou seja, de um universo de mais de 10 mil profissionais, esse dado representa mais de 640 envolvidos diretamente em uma prática criminosa punida com rigor pela lei penal militar.

Tais substâncias estão geralmente associadas à lida com situações de elevado estresse e sobrecarga emocional decorrentes de uma profissáo que fácil e rapidamente esgota mentalmente o seu ocupante. Daí a referida pesquisa ter encontrado que o principal motivo para o uso de drogas do tipo ansiolíticos, calmantes e remédios para o sono sáo justamente as dificuldades na lida diária no labor policial.
Essa não é uma informação que causa surpresa no meio militar. Lee Robins (1974) afirmou que, durante a Guerra do Vietná, o consumo de narcóticos chegou a ser identificado em $43 \%$ da tropa americana em combate. Mesmo depois de terminada a missáo, $10 \%$ do efetivo continuava sob o uso de drogas ilícitas. Anfetaminas e derivados do ópio eram as preferidas.

Em outro estudo, Darryl Arfsten e outros revelaram que, entre 2009 e 2010, 9\% dos policiais no Afeganistáo testaram positivo para algum tipo de droga ilícita, predominantemente tetrahidrocanabinol (maconha). Em Goiás, no Brasil, Sérgio Costa e outros mostraram em artigo publicado em 2015, que 2,34\% da tropa, em uma pesquisa por amostragem, foi testada positivo para algum tipo de entorpecente ilícito (COSTA, et al., 2015). Há ainda a questáo de outras drogas proibidas como anabolizantes, remédios de uso controlado, ansiolíticos e estimulantes que comumente sáo utilizados por policiais militares, diretamente ligadas à profissáo.

Seria possível listar uma enormidade de estudos sobre o tema demonstrando que, embora proibido e punido severamente, o uso de drogas existe e náo pode ser ignorado no meio policial militar. Quando se fala em álcool e tabagismo, a preocupação é ainda maior, pois os resultados demonstram verdadeiro abuso em todos os espectros das corporaçóes. Esses dados, associados aos padróes de respostas dos entrevistados nas diversas pesquisas, mostram que os policiais estáo propensos ao problema em virtude de fatores ligados à funçáa, como o alto nível de estresse ou a impossibilidade de se habituar a situaçóes de violência constante. A válvula de escape encontrada pelo profissional é justamente a drogadiçáo ou o alcoolismo, ou seja, de matéria de direito penal militar, passa-se também a uma questáo de medicina do trabalho e de saúde pública. 


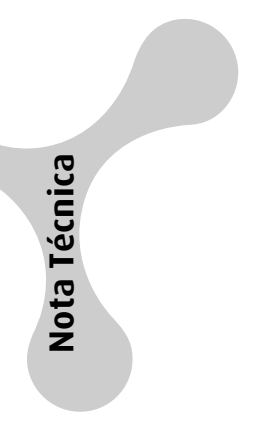

É como condui Ednilsa Souza, no artigo
acima citado:

Ouso de drogaséum fenômeno que acontece na sociedade e não será diferente nas Corporaçóes. É importante que as Polícias Civil e Militar reflitam sobre esta questão de forma a poder oferecer a seus membros um atendimento de qualidade para o uso de substâncias, tendo em vista que têm como missáo oferecer segurança à populaçáo em gera (SOUZA, 2013).

Efetivamente, frente à realidade que se apresenta, parece razoável tratar a questáo de maneira mais abrangente, também como questáo de saúde pública. Não só pelo olhar de atenção e cuidado ao policial, mas também com a atenção do risco associado ao poder de corrosáo das faculdades mentais e fisicas decorrentes do uso de qualquer substância psicoativa por alguém armado e treinado. Ou seja, o problema está relacionado também a uma prestaçáo de serviço público adequado, sendo que esse serviço lida diretamente com direitos fundamentais sensíveis como a vida, a liberdade e a integridade fisica do ser humano.

\section{A Sanção Penal Militar para o Porte de Drogas Frente a Lei de Drogas \\ OCódigo Penal Militar(CPM) aplica-se aos crimes militares ${ }^{2}$. Previsto de formas diferentes na Lei de Drogas e no código castrense, este não distingue entre a conduta da pessoa que possui quantidade ínfima de entorpecente e a conduta do que trafica. Ipso facto ambos seráo abrangidos pelo art. 290 do CPM que assim dispóe:}

Art. 290. Receber, preparar, produzir, vender, fornecer, ainda que gratuitamente, ter em depósito, transportar, trazer consigo, ainda que para uso próprio, guardar, ministrar ou entregar de qualquer forma a consumo substância entorpecente, ou que determine dependência física ou psíquica, em lugar sujeito à administraçáo militar, sem autorizaçáo ou em desacôrdo com determinação legal ou regulamentar:

Pena - redusão, até cinco anos.

A Lei de Drogas, por sua vez, despenalizou a conduta do usuário comum, que seria considerado aquele portador de pequena quantidade da substância, de modo que se deduza ser para consumo próprio. Daí a celeuma que logo veio à tona: seria essa lei, específica, derrogadora do art. 290 do CPM? Ou seria o caso de tê-lo por inconstitucional por não considerar critérios de individualizaçáo, ultima ratio, proporcionalidade e dignidade da pessoa humana, conforme prevê a Carta Magna? E quanto à aplicaçáo do princípio da insignificância, seria possível identificar os atributos que o definem (mínima ofensividade da conduta do agente, nenhuma periculosidade social da açáo, reduzidíssimo grau de reprovabilidade do comportamento e inexpressividade da lesáo jurídica provocada) a depender da quantidade de droga apreendida?

Por algum tempo houve divisão jurisprudencial. Embora o Superior Tribunal Militar sempre entendesse que a Lei nova em nada impactava no mundo castrense, dada a especialidade do direito militar, o Supremo Tribunal Federal divergiu.

\footnotetext{
2 o crime militar segue, no Brasil, o critério do ratione legis, sendo aquele tipificado pelo Código Penal Militar no seu art. $9^{\circ}$. Como dirio Lobão (2011, p. 31), "crime militar é a infração penal previsto na Lei Penal Militar que lesiona bens ou interesses vinculados ò destinação constitucional das instituições militares, às suas atribuições legais, oo seu funcionamento, à sua própria existência, no aspecto particular da disciplina, da hierarquia, da proteção à outoridade militar, e oo serviço militar."
} 
A Segunda Turma do Pretório Excelso reconhecia a aplicação do princípio da insignificância, amparando-se na justificativa de que o art. 290 está incluído no Capítulo III - Dos Crimes contra a Saúde, do diploma castrense. Ou seja, o bem tutelado pela norma seria, primordialmente, a incolumidade pública e em segundo plano estaria a preservação da administração militar, daí porque afirmar que a quantidade ínfima de droga seria uma lesão inexpressiva (à saúde). Senão veja-se o julgado a seguir:

Porte de substância entorpecente. Crime militar (cpm, art. 290). Invocação do princípio da insignificância como fator de descaracterizaçáo material da tipicidade penal. Possibilidade de sua aplicaçáo aos crimes militares. Precedentes da segunda turma do supremo tribunal federal. Medida cautelar deferida. (...) O direito penal não se deve ocupar de condutas que produzam resultado aujo desvalor - por não importar em lesáo significativa a bens jurídicos relevantes - não represente, por isso mesmo, prejuízo importante, (...) Cumpre acentuar, por relevante, que a colenda Segunda Turma desta Suprema Corte tem prestigiado o entendimento ora exposto na presente decisão, reconhecendo aplicável o princípio da insignificância aos crimes militares, mesmo que se cuide de delito de posse de quantidade ínfima de substância entorpecente, para uso próprio, e ainda que se trate de ilícito penal perpetrado no interior de Organizaçáo Militar (HC 90.125/RS, Rel. p/ o acórdāo Min. Eros Grau - HC 93.822/ SP, Rel. Min. Celso de Mello; HC 94.085/SP, Rel. Min. Celso de Mello; HC 94.583/MS, Rel. p/ o acordao Min. Cezar Peluso) STF - HC 97131/RS, Relator Min. Celso de Mello. Julgamento em 10/08/2010.

Contudo, a partir da decisão no $\mathrm{HC}$
103.684/DF, o Pleno do STF consolidou o entendimento que o bem principal tutelado pela norma é a autoridade militar, sendo incabível a adoçáo do princípio da insignificância, conforme transcriçáo a seguir:

Habeas corpus. Crime militar. Conscrito ou recruta do exército brasileiro. Posse de ínfima quantidade de substância entorpecente em recinto sob administração castrense. Inaplicabilidade do postulado da insignificância penal. Incidência da lei civil $n^{o}$ 11.343/2006. Impossibilidade. Resoluçáo do caso pelo critério da especialidade da legislação penal castrense. Ordem denegada. 1. A questáo da posse de entorpecente por militar em recinto castrense não é de quantidade, nem mesmo do tipo de droga que se conseguiu apreender. O problema é de qualidade da relaçáo jurídica entre o particularizado portador da substância entorpecente e a instituição castrense de que ele fazia parte, no instante em que flagrado com a posse da droga em pleno recinto sob administraçáo militar. 2. A tipologia de relaçáo jurídica em ambiente castrense é incompatível com a figura da insignificância penal, pois, independentemente da quantidade ou mesmo da espécie de entorpecente sob a posse do agente, o certo é que não cabe distinguir entre adequaçáo apenas formal e adequaçáo real da conduta ao tipo penal incriminador. STF. HC 103.684/DF. Relator Ministro Ayres Britto. Julgamento em 21/10/2010.

Com este decisum, o STF orientou paradigmaticamente seu entendimento, não afastando a tipicidade em razão da formalidade. É que, por englobar bens distintos, a atipicidade deveria estar amparada em todos os espectros da conduta, o que seria possível em matéria de saúde do agente, mas impossível em sede de preservaçáo da autoridade, pois esta inadmite ponderaçáo. No caso, como afirma Luz (2012), a tipicidade 
formal da norma impediria a valoraçáo material da conduta.

O resultado da aplicaçáo dessa teoria é uma puniçáo que desconsidera questóes subjetivas do autor e do fato, em desalinho com outros direitos previstos na Constituiçáo como a proporcionalidade, a humanidade e a individualizaçáo da pena. Desproporcional também se comparada com o tratamento dispensado ao civil portador de droga em quantidade ínfima, que sequer enfrenta constrição da sua liberdade.

É evidente que a grandeza do bem tutelado pela norma penal militar deve ser protegida. Segurança, vida e defesa das instituiçóes, dos cidadãos e garantia de direitos. Hierarquia e disciplina, sobretudo. É extensa a lista de deveres do militar, em especial do policial militar cujo labor é diuturno, íntimo da populaçáo. Por ser detentor do direito ao uso da força para cumprimento de sua função precípua, a evasáo da condiçáo psíquica normal pelo uso de substâncias entorpecentes, principalmente quando em serviço, representa perigo certo por natureza. Valorosa, pois, a liçáo de Jorge César de Assis nesse sentido:

Se a sociedade ea Pátria lhes outorgam a condição de mantenedores da ordem e defensores das Instituiçóes, aurial que ao lado de tais garantias que muitas vezes escapam ao servidor público civil thes seja exigido com maior rigor o cumprimento de seus deveres. Esta severidade legal, entretanto, não deve passar daqueles dispositivos que realmente o especificam, em salvaguarda do serviço militar, da hierarquia, da condição de superior, não devendo ser estendida aos princípios informadores que regem o direito penal brasileiro, seja ele comum ou militar (ASSIS, 2007)
A manutençáo da disciplina e hierarquia justificam a rigidez da norma. É com base nessa prerrogativa que a aplicaçáo pelos tribunais pátrios adota o viés igualmente rígido. Dentro das casernas, inclusive, paira sobre os policiais a ideia que as auditorias são rigorosas na apuraçáo e punição de crimes que importem justamente na subversáo desses valores tidos como mais caros.

Sáo caros pois encontram guarida na própria Constituiçáo Federal, quando esta impede a concessáo de habeas corpus para puniçóes disciplinares ou quando prevê a prisáo administrativa disciplinar. Nestes casos, vê-se que a prerrogativa da norma é garantir à administração o total controle do mérito de seus atos, o que se coaduna com a disciplina da matéria seja em âmbito civil ou militar. A separaçáo necessária entre a jurisdiçáo e os critérios que privilegiam a discricionariedade administrativa mostra-se plenamente na esfera castrense, contudo, mesmo diante da expressáo da Carta Magna, hoje se tem que o remédio heroico do habeas corpus náo pode discutir o mérito da punição, mas seus critérios de legalidade, competência (RE 338.840).

Ou seja, em um estado democrático de direito, a proteçáo aos direitos fundamentais é empregada na medida de garantir a unidade da Constituiçáa. A ela permeiam os prinápios de humanizaçáo da pena, de intranscendência, do devido processo legal, da vedaçáo à tortura e à escravidão, e com eles convive harmoniosamente a disciplina militar em tempos de guerra ou de paz.

Entretanto, aqui cabe abrir o tema para incluirmos a discussão sobre as funçóes declaradas da pena: a retribuiçáo e a ressocializaçáo. Retribuiçáo no sentido de atribuir um 'castigo' ao in- 
frator da norma ${ }^{3}$; ressocializaçáo na medida em que busca dentro da prevençáo positiva geral e especial atribuir um papel etiológico ao direito penal, elegendo comportamentos condizentes com o devido convívio em sociedade. Para Salo de Carvalho, tais espectros, contudo, ainda que sejam elementos claros da atual política criminal, se desfacelaram com a crise do encarceramento em massa. As prisóes não cumprem seu papel, ainda que tenham servido como anteparo para $o$ emprego de castigos ainda mais severos:

O século XX assistiu ao processo de edificaçáo, de consolidaçăo e de crise das instituiçōes totais punitivas (manicômios e cárcere). Se na constituiçáo do projeto político-criminal oficial da Modernidade a prisão aparece como importante mecanismo humanizador, deixando de ser espaço de sequestro preventivo para substituir as penas cruéis, sobretudo, à pena capital, ao longo do século passado a penitenciária perderá, gradual e definitivamente, a legitimidade auferida pelas teses racionalizadoras de intervençáo. A mudança de rumo dos discursos retributivista e preventivo geral negativo (coação psicológica) em direção à ideia de prevençáo especial positiva é marcada pela alteração da feição estatal absenteísta pela intervencionista (CARVALHO, 2010).

Conforme tratado no item anterior, o consumo da droga é um problema social grave, cultivado por uma sociedade que ainda não consegue garantir direitos básicos para todos. Populaçóes marginalizadas sáo as mais vulneráveis aos efeitos nocivos da droga e o encarceramento não representou soluçáo real para o problema. Nesse sentido é que Fernando Salla e Luiz Claudio Lourenço, ao discutirem a obra de Foucault, afir- mam que

(...) a prisáo não fracassa. Ela cumpre outra tarefa na sociedade e é por isso que ela não é desarmada ou abolida. Ela produz os delinquentes [...], com isso, serviria a uma estratégia de poder dentro da sociedade que ao identificar determinado tipo de delinquência reprimiria e condenaria também certos tipos de ilegalidade, permitindo que outras ilegalidades, especialmente as ilegalidades das elites e outros grupos privilegiados, não fossem reprimidas (SALLA; LOURENÇO, 2014).

As palavras dos autores resumem, em linhas gerais, o que diz a teoria do etiquetamento (ou labelling approach), que em criminologia significa justamente isso: a aproximaçáo da figura do crime à do criminoso.

É possível, contudo, pensar em uma soluçáo que trabalhe o problema de saúde pública e laboral, pensada com fulcro na soluçáo real do problema e náo somente no enrijecimento da lei penal.

Parece também ser o caso de induir a ideia na perspectiva dos direitos humanos dos policiais. José Lauri Bueno de Jesus afirma que a nova tipologia do policial frente aos ditames da democracia implicam no reconhecimento de categorias de direitos universais à profissáo. Em suma, a cidadania é um direito extensível a todos, também aos militares, senão vejamos:

A garantia dos direitos humanos é condição incontestável para o exercício da cidadania, indusive para os policiais militares, o que se constitui num processo contínuo de conquista, cuja via de aces-

3 Para a corrente do funcionalismo moderado, cujo precursor é Claus Roxin, a função retributiva ompara-se na proteção do bem jurídico, sendo o direito penal a ultima ratio em matéria de defesa social. Já para Jakobs, o descumprimento da norma fratura o sistema e, portanto, a pena o restaura, por isso ser mandatório sua devida aplicação. 
so é, sem dúvida, o saber que supóe informação e educaçáo. Os policiais militares, antes de serem policiais, são cidadãos e, como tais, têm direitos e deveres que lhe são inerentes como pessoas humanas (JESUS, 2004).

Arremata o autor afirmando que sáo imprescindíveis o controle e o equilibrio psicológico do policial, fatores determinantes para a saúde emocional da instituiçáo. Há uma necessária transferência desse ambiente na prestaçáo do serviço público, em especial no que tange ao nível de agressividade dispensado ao público (JESUS, 2004).

Nesse sentido éque o agente encarregado da aplicaçáo da lei é também produto do seu meio. Daí deriva-se que o rigor excessivo em determinadas matérias, como esta ora tratada, pode ser um dos afluentes que desbordam no embrutecimento do policial militar. Refletir sobre a questão é, pois, essencial.

\section{Conclusão}

A adoçáo do princípio da insignificância depende da adequação formal e da inadequaçáo material da conduta de maneira que só assim é que se afasta a tipicidade e, por sua vez, o crime. É certo que o bem tutelado pelo Código Penal Militar em seu art. 290 é híbrido; visa tanto à saúde quanto à proteçáo da autoridade militar, e no caso do policial militar tem ainda uma especial carga de desvalor da conduta em virtude da atuaçáo desse agente na repressáo direta desta atividade criminosa no dia-a-dia.

Mas a realidade fática mostra uma situaçáo complicada que talvez não seja resolvida somen- te pelo olhar do direito criminal. Afinal, estaria o militar excluído da sociedade geral que o rodeia de maneira que náo se imiscui ou toca nos graves problemas sociais da atualidade? E além disso, é a privaçáo de liberdade soluçáo? A sançáo estipulada trará o conforto e paz sociais necessários, terá funçáo efetiva na coesáo social e será mesmo dotada da coercitividade que impede os outros de praticar o mesmo ato?

O fato é que desde a entrada em vigor da Lei de Drogas, foi despenalizado o crime de porte de substância proibida para consumo próprio em pequena quantidade para o usuário comum. Entretanto persiste no meio militar a dura igualdade formal entre este e o traficante, em que pese a evoluçáo do tratamento dado ao meio civil.

A natureza deste trabalho é reflexiva dessa questão. O consumo de drogas eálcool no meio policial e militar também está ligado ao alto nível de estresse da profissáo, e esse tema demanda soluçóes que passem por contornar o problema para além do direito penal e das penitenciárias. É necessário humanizar o direito penal militar e inseri-lo no contexto atual em que a sociedade luta para resolver um de seus mais graves problemas. A justiça e as instituiçóes militares devem mais que nunca ser parceiras da sociedade nesse processo, pois dele não estáo isentas.

É, por fim, matéria de medicina laboral, de direitos humanos do profissional policial e de incluir a categoria na resoluçáo conjunta de uma verdadeira epidemia que afeta milhóes de pessoas mundo afora. 


\section{Referências Bibliográficas}

ARFSTEN, Darryl P ; MORALEZ, Joe F ; CHESTER, Linnes L ; MOHAMAD, Pir ; WEBER, Timothy H. Drug use among the Afghanistan National Police: a national assessment. Military Medicine, v. 177, n.1, 2012, pp. 85-90.

ASSIS, Jorge César de. Direito Militar: aspectos penais, processuais penais e administrativos. Juruá Editora, 2007.

BRETAS, Marcos Luiz; SANT'ANNA, Marilene Antunes. Crime e punição na história. In: LIMA, Renato Sérgio de; RATTON, José Luiz; AZEVEDO, Rodrigo Ghiringhelli de (Orgs.). Crime, Polícia e Justiça no Brasil. São Paulo: Contexto, 2014.

CARVALHO, Salo de. Substititutivos penais na era do grande encarceramento. Res Severa Verum Gaudium, v. 2, ก. 1, 2010.

COSTA, Sérgio Henrique Nascente; YONAMINE, Maurício; RAMOS, Andrea Luciana Martins; OLIVEIRA, Fernando Gomes Ferreira; RODRIGUES, Caroline Rego; CUNHA, Luiz Carlos da. Prevalência do uso de drogas psicotrópicas em unidades da polícia militar. Ciência \& Saúde Coletiva, v.20, n.6, 2015, pp. 1843-1849.

FAYET JUNIOR, Ney; FLORES, Carlos Thompson. Penas e Punição. In: LIMA,Renato Sérgio de; RATTON,José Luiz; AZEVEDO, Rodrigo Ghiringhelli de (Orgs.). Crime, Polícia e Justiça no Brasil. São Paulo: Contexto, 2014.
LEMGRUBER, Julita; BOITEUX, Luciana. 0 fracasso da guerra às drogas. In: LIMA, Renato Sérgio de; RATTON,JOsé Luiz; AZEVEDO, Rodrigo Ghiringhelli de (Orgs.). Crime, Polícia e Justiça no Brasil. São Paulo: Contexto, 2014.

LOBÃO, Célio. Comentários ao Código Penal Militar: Parte Geral. v. 1. Rio de Janeiro: Forense, 2011.

LUZ, Yuri Corrêa da. Princípio da insignificância em matéria penal: entre aceitação ampla e aplicação problemática. Revista Direito GV, v. 8, n. 1, 2012, pp. 203 -233.

ROBINS, Lee N. et al. How permanent was Vietnam drug addiction? American journal of Public Health, v. 64, 1974, pp. 38-43.

SALGADO, Gisele Mascarelli. Sanção na teoria do direito de Norberto Bobbio. Juruá Editora, 2010.

SHECAIRA, Salomão. Drogas e Criminologia. In: LIMA,Renato Sérgio de; RATTON,José Luiz; AZEVEDO, Rodrigo Ghiringhelli de (Orgs.). Crime, Polícia e Justiça no Brasil. São Paulo: Contexto, 2014.

SOUZA, Ednilsa Ramos de. Consumo de substâncias lícitas e ilícitas por policiais da cidade do Rio de Janeiro. Ciência \& Saúde Coletiva, v.18, 2013, p. 667-676. 



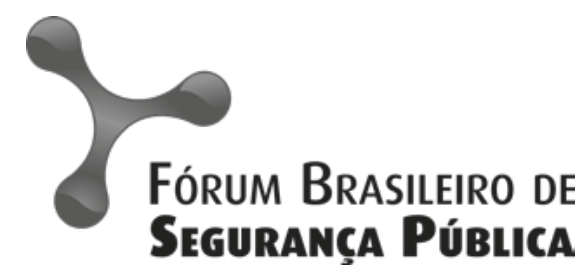

ISSN 1981-1659 